\title{
BASES PARA UN FUTURO DERECHO PENAL INTERNACIONAL DEL MEDIO AMBIENTE
}

\author{
Adán NIETO MARTÍN*
}

\begin{abstract}
Resumen
El artículo aboga por que los delitos contra el medio ambiente cometidos por empresas multinacionales, constituyan un nuevo ámbito de intervención del derecho penal internacional. El medio ambiente constituye un bien jurídico global, cuya tutela por los ordenamientos nacionales no siempre resulta eficaz. El trabajo propone la tipificación de una serie de delitos comunes y un sistema de responsabilidad basado en el castigo de las personas jurídicas.
\end{abstract}

\section{Palabras clave}

Delitos contra el medio ambiente, derecho penal internacional, responsabilidad de las empresas internacionales, responsabilidad penal de personas jurídicas.

\section{Key words}

Crimes against the environment, international criminal law, responsibility of international corporations, responsibility of legal persons.

SUMARIO: I. Introducción; II. Multinacionales, soberanía, derecho al desarrollo y medio ambiente; III. ¿Cuáles podrían ser los tipos penales de un hipotético derecho penal internacional del medio ambiente?; 1. Medio ambiente y derechos humanos: el genocidio ecológico; 2. Daños contra el medio ambiente de carácter transnacional: tráfico ilícitos y delito ecológico transfronterizo; 3. Macrodaños ambientales: el delito de geocidio; 4. Medio ambiente y expoliación de recursos naturales: el patrimonicidio; 5. Algunas conclusiones sobre la tipificación de las infracciones del derecho penal internacional del medio ambiente; IV. Los responsables: la responsabilidad penal de las multinacionales; 1 . La responsabilidad penal de las personas jurídicas en el derecho internacional; 2. El sistema de imputación: la culpabilidad de empresa; 3 . Las infracciones: el defecto de organización como infracción autónoma y la transparencia en la responsabilidad social corporativa.

* Catedrático de Derecho Penal. Universidad de Castilla-La Mancha. Subdirector del Instituto de Derecho Penal Europeo e Internacional. 


\section{INTRODUCCIÓN}

T OS atentados contra el medio ambiente cometidos por empresas multinaciona-

les tienen una estructura similar a los ataques contra los derechos humanos que han dado lugar al nacimiento de la Corte Penal Internacional. Esta semejanza descansa en dos argumentos. De un lado, se ha instaurado la conciencia de que la protección del medio ambiente es una tarea global, cuya efectiva tutela no debe depender de la capacidad de un determinado Estado para implementar una normativa razonablemente protectora del medio ambiente y sancionar eficazmente sus infracciones. Al igual que la sanción a la violación de los derechos humanos no puede depender de la voluntad o la eficacia del sistema judicial de un país, los atentados más graves contra el medio ambiente han dejado de ser un asunto nacional para convertirse en una materia de gobernanza global. De otro lado, cuando estos atentados son cometidos por grandes multinacionales existe una asimetría entre la capacidad de los sistemas judiciales de muchos países para juzgarlas y la capacidad de las multinacionales para evitar cualquier tipo de control eficaz.

A la vista de esta similitud, sería razonable que a medio o corto plazo los organismos internacionales se pusieran en marcha hacía la creación de un derecho penal internacional del medio ambiente, con el establecimiento incluso de un tribunal supranacional que castigara estos delitos y se ocupara de cuestiones medioambientales. En los últimos meses algunas iniciativas muestran que algo empieza a moverse en esta dirección(1).

El presente trabajo pretende reflexionar sobre los dos pilares en los que debe descansar esta regulación internacional. El primero es una normativa común, fruto de un proceso de armonización, que requiere diseñar tipos comunes basados en las normas de derecho internacional del medio ambiente y las Convenciones internacionales en materia penal, como particularmente el Convenio del Consejo de Europa o las Directivas de la Unión Europea (vid. III). El segundo pilar de este derecho penal internacional del medio ambiente debe ser la responsabilidad colectiva (vid. IV). Los problemas de enforcement que conllevaría la implementación eficaz de un derecho penal internacional en esta materia, solo puede solventarse si, conjuntamente con la vía de la responsabilidad penal individual, se apuesta con fuerza por la responsabilidad de las personas jurídicas. Una línea de política criminal que en

(1) Con carácter general, vid. Nowak, M. y Kosma, J. «A World Court of Human Rights», Swiss Intiative to Commemorate the 60th Anniversary of The UDHR: Protecting Dignity: An Agenda for Human Rights, disponible en: http://www.udhr60.ch/report/hrCourt-Nowak0609.pdf, que incluye a los actores no estatales como responsables directos de la violación de derechos humanos. Favorables a un tribunal internacional especializado en la protección del medio ambiente, cf. McCALLION, K y Sharma, R., «Environmental Justice without Borders: The Need for an International Court of the Environment to Protect Fundamental Environmental Rights», Geo. Wash. J. Int'1 L. \& Econ, Vol. 32, 1999-2000, pp. 351 y ss. En materia medioambiental, destaca el activismo del «eje bolivariano» compuesto por Bolivia, Venezuela y Ecuador, cuyas nuevas constituciones tienen en común una nueva visión del medio ambiente, conectada con la cosmovisión de los pueblos precolombinos. El actual gobierno boliviano, por ejemplo, ha solicitado la creación de un tribunal internacional de justicia climática, con este fin ha creado la denominada Plataforma Energética (http://plataformaenergetica.org). Dentro de este movimiento habría que encuadrar también la reciente demanda el 26-11-2010 que se ha presentado en Ecuador contra British Petroleum, utilizando el principio de jurisdicción universal y amparándose en la amplia protección que la Constitución ecuatoriana de 2008 presta al medio ambiente. 
la actualidad resulta discutida en el derecho internacional, como prueba el que su inclusión no fue admitida en el Estatuto de Roma.

Antes de acometer ambas tareas, fundamentaré con algo más de detalle, el punto de partida, es decir, por qué existe una identidad estructural entre los atentados contra el medio ambiente cometidos por multinacionales y el derecho penal internacional y por qué la armonización y la responsabilidad de las personas jurídicas deben ser sus bases (vid. II).

\section{MULTINACIONALES, SOBERANÍA, DERECHO AL DESARROLLO Y MEDIO AMBIENTE}

La impotencia de los derechos nacionales para sancionar a las empresas multinacionales, que han ocasionado graves daños al medio ambiente, cobra toda su crudeza cuando el atentado tiene lugar en el territorio de un país con un ordenamiento jurídico débil, baja calidad institucional y grandes deseos de atraer inversiones extranjeras. El caso Bohpal ha sido utilizado en la literatura para demostrar los problemas con que pude encontrase un Estado como la India, para sancionar penalmente o incluso pedir responsabilidades civiles en uno de los desastres ecológicos más graves de la historia (2). La altivez de la multinacional Dow Chemical frente al gobierno y las autoridades indias, esgrimiendo los argumentos más inverosímiles para negar su responsabilidad, contrasta con las buenas maneras y la disponibilidad que hoy, por ejemplo, apreciamos en British Petrolium ante el gobierno de los Estados Unidos (3).

Esta constatación pone de manifiesto algo que desde hace algunos años viene denunciando la green criminology(4), que en los delitos contra el medio ambiente existe un importante factor de discriminación. La normativa ecológica más avanzada y rigurosa de los países desarrollados ha trasladado los atentados contra el medio ambiente a países subdesarrollados. Estos Estados han aceptado ser «países basureros», admitiendo los residuos que compran a los países más desarrollados, o convertirse en centros de producción de las grandes firmas, a costa de rebajar al máximo los costes de producción derivados del medio ambiente, o permitir la explotación de sus recursos naturales sin consideración alguna hacía el medio ambiente o los derechos más básicos de las poblaciones indígenas afectadas. No pocas veces esta debilidad o tolerancia legislativa se extiende a la fase de comercialización de los productos. La historia de los pesticidas o medicamentos prohibidos en el primer mundo,

(2) Vid. Perce, F. y Tombs, S., «Bohpal: Union Carbide and the Hubris of the Capitalist Technocracy», Social Justice, Vol. 16, núm. 2, 1989, pp. 116 y ss., tomando el caso Bopahl como paradigma de los problemas de la protección del medio ambiente; CAssels, J., «Outlaws: Multinational Corporations and Catastrophic Law», Cumb. L. Rev., Vol. 31, 2000-2001, pp. 31 y ss.

(3) Vid. la contundente reacción del presidente de los Estados Unidos, «Remarks by the President to the Nation on the BP Oil Spill», 15-10-2010, The White House, Office of the Press Secretary.

(4) Sobre la green criminology, vid. GibBs, C., Gore, M., McGarrell, E. y Rivers, L., «Introducing Conservation Criminology», Brit. J. Criminol., Vol. 50, 2010, pp. 124 ss.; RoB, W., «Environmental crime in global context», Current Issues Crim. Just., 16, 2004-2005, p. 275; para una revisión crítica de conjunto Halsey, M., «Against "green" criminology», Brit. J. Criminol., Vol. 44, 2004, pp. 833 y ss. 
por ser altamente perjudiciales para la salud, pero comercializados y utilizados durante años en países subdesarrollados, es sobradamente conocida.

Cuando la actividad de las grandes empresas multinacionales causa o supone un peligro de deterioro grave y permanente para el medio ambiente, y además afecta a la salud de un número indeterminado de personas, esta situación deja de ser un problema local o nacional, para transformase en una cuestión de protección a los derechos humanos perteneciente al derecho internacional e internacional penal (5). En algunos supuestos, incluso, los atentados ecológicos han ido unidos directamente a la comisión de delitos muy graves, como el que dio lugar a la mítica decisión Doe v. Unocal (6), en la que por primera vez una empresa multinacional fue condenada por la violación de derechos humanos. En este caso dos grupos petroquímicos Unocal (EE.UU.) y Total (Francia), se beneficiaban de las violaciones a los derechos humanos realizadas por la junta militar de Birmania, al objeto de construir un gasoducto. En este mismo caso la justicia belga tras otra decisión clave, utilizando el principio de justicia universal, mantuvo la existencia de jurisdicción para juzgar a los responsables de la empresa Total por crímenes contra la humanidad(7).

Aunque partiendo de la lógica de la subsidiariedad y de la soberanía, los Estados en donde ha tenido lugar el atentado contra el medio ambiente debieran ser competentes en primer término para juzgarlo, ello no siempre es posible. Los casos de atentados medioambientales en países del tercer mundo muestran, efectivamente, que la falta de capacidad técnica o de medios impide a la administración hacer cumplir la legislación sobre el medio ambiente(8). A ello debe sumársele la ineficacia posterior de la administración de justicia y, en ocasiones, situaciones de corrupción generalizada.

Hasta aquí, tal como antes señalaba, existe una gran identidad estructural con la situación que ha dado origen al derecho penal internacional. No obstante, existen tres factores que marcan diferencias significativas.

Muchos de los atentados contra el medio ambiente que tienen lugar en estos países son absolutamente legales. A veces porque gracias a la corrupción, la legislación se ha moldeado para que quepan en ella conductas devastadoras contra el medio ambiente. Pero también en otras ocasiones porque los gobiernos invocando su derecho al desarrollo deciden ser legislativamente amables con estas empresas, buscando la creación de empleo. El principio de soberanía sobre los propios recursos es en este punto un arma de doble filo, pues puede invocarse tanto para defender los recursos naturales frente a agresiones al medio ambiente, como para explotarlos desmedidamente. El concepto de desarrollo sostenible, acuñado en la

(5) En general se habla de la corporate complicity para referirse a los supuestos de implicación de las empresas multinacionales en ataques a los derechos humanos, este concepto suele abarcar conjuntamente la responsabilidad penal y la civil, vid. Report of the International Commission of Jurist Experts Legal Panel on Corporate Complicity in International Crime, Ginebra, 2008.

(6) Doe v Unocal, 963 Supp 880 (CD Cal 1997).

(7) Actions Birmanie, La Cour d'Arbitrage relance le dossier Total en Birmania, Communiqué de presse, 22 juin 2006.

(8) Cfr. Sobre los problemas de enforcement Cassels, D., «Corporate Aiding and Abetting of Human Rights Violations: Confusion in the Courts», Journal of International Human Rights, Vol 6 , Issue. 2, 2008, pp. 7 y ss.; Morimoто, T., Growing industrialization and our damaged planet. The extraterritorial application of developed countries environmental law to transnational corporations abroad, Utrecht Law Rev., Vol I, Issue 2, 2005, pp. 144 y ss. 
Declaración de Río de 1992, refleja precisamente la tensión latente entre las demandas proteccionistas (9), las aspiraciones al desarrollo y el derecho de cada país a ponderar de manera autónoma estos dos intereses en juego a la hora de conformar su legislación(10).

Por estas mismas razones que acaban de apuntarse, la legislación internacional en materia de medio ambiente no ha desarrollado estándares o contenidos comunes como los que existen en relación a los derechos humanos, fuera de ámbitos muy concretos (11). De este modo, se está aún lejos de alcanzar que el derecho al medio ambiente sea considerado un derecho fundamental, pese a que la Convención interamericana de derechos humanos y la africana lo incluyan expresamente en su texto o en protocolos adicionales, y aparezca cada vez más entre los derechos fundamentales de tercera generación en bastantes constituciones nacionales.

Mas el escaso desarrollo de la legislación internacional también se debe a que hasta ahora las empresas multinacionales, que serían sus principales destinatarias, han conseguido que las organizaciones internacionales apuesten por la estrategia reguladora que más les conviene: el soft law y la autorregulación(12). La OCDE o Naciones Unidas basan su estrategia en códigos éticos e instrumentos que como el Global Compact confían en que las grandes empresas a través de la autorregulación interna, la invocación de su responsabilidad social y la amenaza de sanciones reputacionales van a ser suficientes para que cumplan unos compromisos mínimos en la materia(13). De este modo, lo normal es que las multinacionales apliquen estándares medioambientales distintos en su país de procedencia, y aquellos en los que tienen sus bases operacionales. Son muy pocos los casos en los que estas se dotan de una política medioambiental propia, que sobre la base de la legislación de su estado de origen se aplica a todos los lugares en los que actúen(14).

El tercer factor diferencial es la deslocalización de la responsabilidad. Las empresas multinacionales están organizadas como grupos de empresas, creando

(9) Cfr. El Principio 11 de la Declaración de Río menciona que: «States shall enact effective environmental legislation. Environmental standards, management objectives and priorities should reflect the environmental and development context to which they apply. Standards applied by some countries may be inappropriate and of unwarranted economic and social cost to other countries, in particular developing countries.»

(10) Cfr. Cassels, J., «Outlaws» op. cit., pp. 316 y ss; para un país tan significativo como China, vid. Wang, S., «New Developments of Environmental Policy and Environmental Criminal Law in the People's Republic of China», ZIS, 2010.

(11) El único caso de estándar común son los protocolos de Montreal sobre substancias que dañan la capa de ozono y la Convención de Naciones Unidas sobre el cambio climático. La falta de desarrollo de esta Convención, tras el fracaso de la reunión de Copenhage de 2010 muestra precisamente la dificultad de llegar a fijar estándares comunes.

(12) Para una visión de conjunto Zubizarreta, J., Las empresas transnacionales frente a los derechos humanos: la historia de una asimetría normativa, Hegoa, Bilbao, 2009.

(13) Cfr. Shanghnessy, «The United Nations Global Compact and then Continuing Debate about the Effectiviness of Corporate Voluntary codes of Conduct», Colo. J. Int'l Envtl. L. \& Pol., Vol. 12, 2001, pp. 159 y ss; Stephens, B., «The Amorality of Profit: Transnational Corporations and Human Rights», Berkeley J. Int'1 L., Vol. 20, 2002, pp. 45 y ss.; ZondoraK, V., «A new face in corporate environmental responsibility: The Valdez Principles», Environmental Affairs, Vol. 18, 1991, pp. 471 y ss. (favorable al soft law y la autorregulación); también favorable a la autorregulación desde los presupuestos del derecho reflexivo de Teubner, ORTs, E., «Reflexive Environmental Law», Northwestern University Law Journal, Vol. 89, 1994-1995, p. 1.227.

(14) Cfr. Morimoto, T., op. cit., pp. 137 y ss. 
filiales con personalidad jurídica independiente en los países en los que actúan. Mediante una estrategia inteligente, desde el punto de vista de la responsabilidad civil o penal, suelen indicar que el control operacional, reside en manos de los responsables locales, reservándose la matriz un control de la estrategia global. Como lógicamente los errores que dan lugar al desastre ecológico se producen en las concretas operaciones de producción o fabricación, las sociedades matrices suelen esgrimir este argumento con el fin de descargar toda responsabilidad sobre la filial. El caso del Bhopal es nuevamente un buen ejemplo(15).

En otros casos la deslocalización se consigue utilizando sociedades pantalla con sede en paraísos jurídicos. Este tipo de maniobras son frecuentes en el caso de los atentados contra el medio ambiente marino. Los buques petroleros o las plataformas petroleras se matriculan en países inverosímiles que les garantizan la ausencia de controles y, en caso de que se produzca algún proceso penal, la dificultad de obtener cooperación judicial, para por ejemplo embargar los bienes de la compañía (16).

Estas aristas diferenciales, a la vez que muestran los problemas para que surja un derecho penal internacional del medio ambiente, apuntan también a cuáles deben ser las características y estrategias principales de este derecho penal. El problema principal, que desde el punto de vista técnico deben salvar la armonización internacional de los delitos contra el medio ambiente, es que en la mayoría de los ordenamientos la realización de un delito contra el medio ambiente requiere que se haya infringido algún tipo de norma administrativa. La descripción de la conducta prohibida en los delitos contra el medio ambiente se efectúa recurriendo a las normas penales en blanco o mediante un precepto penal de carácter accesorio que sanciona la infracción a una determinada norma administrativa (17). Los comportamientos típicos del medio ambiente no sólo tienen que ser efectivamente o potencialmente lesivos para el medio ambiente, sino que sobre todo deben contravenir la normativa medioambiental o realizarse sin haber obtenido una autorización administrativa. De existir una normativa internacional medioambiental suficientemente desarrollada, ésta estaría llamada a ser la normativa de complemento o de referencia de la norma penal, pero dada su inexistencia todo aconseja a que los delitos internacionales contra el medio ambiente castiguen directamente el comportamiento lesivo o potencialmente lesivo, sin necesidad de constatar la infracción de la normativa nacional. Esta pretensión, como después se verá, ocasiona un grave problema de falta de precisión en la descripción de comportamientos típicos.

La necesidad de desvincular los delitos internacionales contra el medio ambiente de la normativa medioambiental administrativa ocasiona que ni la Directiva de la UE relativa a la protección del medio ambiente en materia penal, ni el Convenio del Consejo de Europa, pueden ser modelos del futuro derecho penal internacional. El que las dos muestras más importantes de Convenios internacionales en esta materia no puedan servir de punto de partida dificulta la armonización global de esta materia. La Directiva vincula todas sus infracciones a la violación de

(15) Cfr. Cassels, J. Outlaws op. cit., pp. 11 y ss.

(16) Cfr Sherfe, «Desastres ecológicos y banderas de conveniencia. Como BP se burla de la Ley», L'monde diplomatique, edición en Español, agosto 2010, núm. 178.

(17) En relación a los países de la UE, Delage, G., «Le Droit pénal de l'environment, en Giudicelli Dellage (sous la direction) Droit pénal des affaires en Europe», PUF, 2006, pp. 487 y ss. 
una normativa de la propia EU en materia del medio ambiente(18). Todos los comportamientos sancionados han de ser, en este sentido, «ilícitos». E igual ocurre con cuatro de los cinco comportamientos a los que se refiere la Convención del Consejo de Europa. Únicamente el primero de ellos se desvincula de la infracción de cualquier normativa ambiental(19).

La segunda característica de los atentados contra el medio ambiente, tal como antes señalábamos, reside en que sus protagonistas son empresas internacionales, en las que va a resultar muy difícil establecer la responsabilidad de sus máximos dirigentes. Si el derecho penal contra el medio ambiente apostara en exclusiva por la responsabilidad individual, tal como se hace en el Estatuto de la Corte Penal Internacional, normalmente las personas castigadas serían, en el mejor de los casos, los directivos o ejecutivos de las empresas filiales. En ocasiones la responsabilidad recaería incluso sobre los técnicos o empleados que serían los responsables de haber cometido el «fallo operacional» que ha dado lugar a los daños contra el medio ambiente, de nuevo aquí el caso del Bohpal puede servirnos de ejemplo (20).

Mas éste problema no es en absoluto nuevo. De hecho, en el derecho penal internacional «clásico» ha existido un problema semejante: cómo imputar a los superiores jerárquicos que han ordenado u organizado una masacre, cuando sus ejecutores han sido, por ejemplo, simples soldados (21). Algunas de las teorías que se han acuñado en este terreno como la autoría mediata a través de los aparatos organizados de poder, la redefinición de la coautoría o la comisión por omisión son, en principio y teóricamente, posibles de aplicar a algunos supuestos de delitos contra el medio ambiente cometidos por empresas multinacionales. No obstante, la mejor forma de asegurar que los dirigentes de la empresa matriz van a estar interesados en que sus empresas filiales respeten la legalidad medioambiental es la responsabilidad de las personas jurídicas. La responsabilidad colectiva nace precisamente para acabar con la irresponsabilidad de los centros de poder en los delitos cometidos por organizaciones.

\section{III. ¿CUÁLES PODRÍAN SER LOS TIPOS PENALES DE UN HIPOTÉTICO DERECHO PENAL INTERNACIONAL DEL MEDIO AMBIENTE?}

Aunque el derecho internacional del medio ambiente no tiene un grado de desarrollo semejante al de los derechos humanos (22), existan algunos consensos básicos sobre los que se puede empezar a estructurar la intervención del derecho

(18) Cfr. Llados, B., Nuevas perspectivas de la política criminal europea en materia medioambiental, Atelier, 2008.

(19) A medio plazo, la posibilidad de construir un derecho penal internacional del medio ambiente basado en la accesoriedad con la normativa medio ambiental, podría abrirse paso si se adoptaran algunas propuestas como la aplicación a las sociedades multinacionales por los estados de acogida de la legislación vigente en su país de origen, al respecto, Morimoto, T., op. cit., passim.

(20) Vid. Perce, F., y Tombs, S., op. cit., pp. 116 y ss.

(21) Por todos, Cabana, F., Responsabilidad penal del dirigente en estructuras jerárquicas, Tirant lo Blanch, 2003.

(22) Sobre el derecho internacional del medio ambiente, vid. Calvo, L., Derecho internacional del medio ambiente, Atelier, Barcelona, 2005. 
penal(23). Estas cuatro líneas son: (a) la reconducción de los atentados al medio ambiente a atentados contra los derechos humanos de primera generación; (b) la consideración de las daños ambientales como daños económicos que afectan al derecho -ampliamente reconocido por el derecho internacional- a la explotación de los propios recursos naturales; (c) la sanción de los macrodaños ambientales; (d) los daños contra el medio ambiente de carácter transnacional.

\section{MEDIO AMBIENTE Y DERECHOS HUMANOS: EL GENOCIDIO ECOLÓGICO}

La conexión entre medio ambiente y derechos humanos ha constituido la forma más directa de dar entrada al medio ambiente dentro del derecho internacional (24). Esta primera aproximación se efectúa por dos caminos diferentes. El primero es el seguido en solitario por la CEDH que, como vamos a ver, a través de una interpretación muy progresiva del Convenio ha considerado contrarios a los derechos en él reconocidos a daños medioambientales de carácter leve o medio. La segunda línea es la seguida por el resto de tribunales internacionales: El Tribunal africano de derechos humanos y la Corte Interamericana, el Comité de Derechos Humanos de Naciones Unidas. En esta senda se mueve también la jurisprudencia norteamericana relativa a la Alien Tort Act. Esta línea jurisprudencial es mucho más estricta. Las violaciones al medio ambiente solo se reconducen a violaciones a los derechos humanos en supuestos mucho más graves, en los que se pone en peligro la supervivencia o la salud de poblaciones enteras por la emisión de gases contaminantes, la polución de las aguas, o la explotación industrial va acompañada de violaciones muy serias a los derechos humanos como trabajos forzados, asesinatos, etc.

El TEDH ha desarrollado, como indicaba, una jurisprudencia muy imaginativa que utiliza el derecho a la vida privada y familiar (art. $8 \mathrm{CEDH}$ ) para proteger el medio ambiente. Los Estados infringen este derecho cuando no adoptan las medidas necesarias para evitar los insoportable olores de una planta depuradora de residuos (25), permiten la construcción de una central nuclear a menos de 300 del domicilio de la demandante (26), no evitan los ruidos ocasionados por el aeropuerto de Heathrow (27) o no proporcionar información suficiente en aquellas ocasiones en que un gobierno se embarca en operaciones peligrosas (28).

Aunque la eficacia horizontal de los derechos humanos está reconocida desde hace tiempo y, por tanto, no puede dudarse que afectan al comportamiento de

(23) Sobre las estrategias de protección al medio ambiente en el contexto normativo actual, vid. por ejemplo, CASSEL, J., Enforcing Environmental Human Rights: Slected Strategies for US NGOs, Northwestern Journal of International Human Rights, Vol. 6, 2007, pp. 104 y ss; OsOFSKY, H., «Learning from Environmental Justice: A Nex Model for International Environmental Rights», Satandford Environmental Law Journal, Vol. 24, 2005, pp. 71 y ss.

(24) Sobre la evolución del derecho al medio ambiente en el derecho internacional, vid. ATAPAttu, S., «The Right to a Healthy Life or the Right to Die Polluted?: The Emergence of a Human Right under International Law», Tulane Environmental Law Journal, Vol. 16, 2002-2003, p. 65.

(25) TEDH, 9-12-1994, Lopez Ostra c. España,

(26) Comm. EDH núm. 13728/88, decisión del 17-5- 1990.

(27) TEDH, Pollwell et Rayner c. Reino Unido, 21-2-1990

(28) TEDH, Anna Maria Guerra y otros c. Italia, 19-2-1998. 
las empresas multinacionales, la Corte no es competente para conocer las violaciones que proceden de personas o corporaciones no estatales. En un plano puramente normativo este problema podría solucionarse utilizando otro de los desarrollos jurisprudenciales más importantes del TEDH: los Estados no solo infringen el Convenio cuando directamente con su actividad lesionan alguno de los derechos reconocidos, sino también cuando una vez lesionados no realizan investigaciones eficaces para descubrir y sancionar adecuadamente a los culpables. De este modo, aunque las empresas multinacionales no puedan ser directamente demandadas, indirectamente la doctrina de las obligaciones de tutela sirve para obligar a los Estados a generar un derecho penal eficaz para castigar sus abusos. Una vía a explorar es si, a partir de la posibilidad de aplicación extraterritorial del CEDH; que a través de diversas vías ha auspiciado el Tribunal, cabría establecer una obligación a los Estados miembros para que prevengan o sancionen las violaciones del Convenio realizadas por sus empresas multinacionales en países terceros.

Frente a la jurisprudencia del TEDH, las Cortes regionales africana e interamericana sólo han conectado medio ambiente y derechos humanos en casos mucho más brutales e igual línea ha seguido la Comisión de Derechos Humanos de Naciones Unidas. En la Corte Interamericana (29) el caso más emblemático es la condena al gobierno brasileño por su pretensión de construir una autopista atravesando la Amazonia, lo que podía poner en serio peligro la supervivencia de los Yanomamis, al introducir enfermedades para las cuales estaban indefensos y destruir sus medios de subsistencia. Dentro de esta línea de macro daños, la Comisión de Derechos Humanos de Naciones Unidas, consideró que violaba el derecho a la vida del artículo 6 del CEDH la pretensión de Canadá de instalar un gigantesco cementerio nuclear cercano a una población(30).

Más allá de las cortes regionales de derechos humanos y la Comisión de Naciones Unidas, la Alien Tort Claim Act (ATCA) en los Estados Unidos representa en la actualidad el único instrumento que puede aplicarse a actores privados por violaciones al derecho al medio ambiente, con sanciones de rasgos punitivos, y con un marco de aplicación que se asemeja al principio de justicia universal. La ATCA acuñada en 1789 sanciona cualquier infracción a la law of nations, lo que los tribunales norteamericanos interpretan como la infracción de la costumbre internacional, lo que comprendería tanto las normas de ius cogens que forman el núcleo indiscutible de este concepto, como incluso tratados multinacionales con numerosos firmantes. La jurisprudencia sobre la ATCA establece con claridad que prohibiciones como la tortura, la esclavitud, el genocidio, los crímenes de guerra, las detenciones arbitrarias, los tratos inhumanos o degradantes y un buen número de las violaciones más graves a los derechos humanos conforman violaciones a la law of nations (31).

(29) La Convención Americana de Derechos Humanos cuenta actualmente con un protocolo adicional sobre derechos humanos en materia de derechos económicos, sociales y culturales, el «Protocolo de San Salvador», que recoge el derecho al medio ambiente.

(30) Cfr. Atapattu, S., op. cit., pp. 87 y 99 y ss.

(31) La bibliografía sobre la ATCA es muy extensa. Vid. por ejemplo, Davis, J., «Justice Without Borders: Human Rights Cases in U. S. Courts», Law \& Policy, Vol. 28, núm. 1, 2006; JosePH, S., Corporations and Transnational Human Rights Litigation, Hart Publishing, Oxford, 2004, pp. 21 y ss. 
En materia de medio ambiente el supuesto más emblemático es el ya citado caso Doe v. Unocal (32). Este caso es importante por dos razones. Primero porque fue el primero que consideró que la ATCA no se ceñía únicamente a violaciones procedentes del Estado o sus agentes, sino también a individuos y, como era el caso, empresas multinacionales. A partir de Unocal, son muchas las multinacionales que se han tenido que enfrentar con demandas basadas en la ATCA (Shell, Río Tinto, Freeport McMoran, Exxon, Pfizer, Coca Cola...). No obstante, y como después veremos con más detalle una reciente -y sorprendente- decisión del Tribunal de apelaciones del segundo circuito Köbel v. Royal Dutch Petroleum Co., ha señalado que no forma parte de la costumbre internacional la responsabilidad de las personas jurídicas por delitos como torturas, crímenes de guerra o contra la humanidad.

Segundo, porque conecta las violaciones al medio ambiente con violaciones a derechos humanos que considera incluidas indubitadamente bajo la law of nations. Como ya señalamos, un grupo de agricultores de Myanmar demandaron a Unocal porque en conjunción con las fuerzas armadas y policiales del país había cometido graves atentados contra los derechos humanos (torturas, trabajos forzados, violaciones, asesinatos) en la construcción de un oleoducto en el interior del país.

Tras Unocal los intentos de utilizar la ATCA en relación a atentados contra el medio ambiente han sido numerosos (33). Las conclusiones de esta jurisprudencia medioambiental podrían ser las siguientes. De un lado, los tribunales afirman que el derecho al medio ambiente, de modo autónomo, no forma parte de la costumbre internacional. En el asunto Baenal v. Freeport McMoran(34), donde los recurrentes utilizaban a su favor varios textos internacionales como la declaración de Río, el tribunal señaló que las normas internacionales en materia de medio ambiente no sirven para conforman un estándar de protección mínimamente articulado. Es más, acogiendo expresamente el derecho a la soberanía sobre los propios recursos la sentencia indica que «the argument to abstain from interfering in a sovereign's environmental practicies carries persuasive force especially when the alleged environmental torts and abuses occur within the sovereign's borders and do no affect neighboring countries». Incluso, cuando cambiando de táctica, los demandantes conectan el daño al medio ambiente con el derecho a la vida o la salud, alegando una situación de peligro, los tribunales han negado que exista un estándar internacional reconocible en este punto. De otro lado, de la propia decisión Baenal, así como de algunas otras decisiones como Aguinda v. Texaco (35), en la que los daños medioambientales de la filial de Texaco en Ecuador se extendieron a Perú, o del asunto Sarei v. Riotinto, en el que la contaminación se extendió a aguas internacionales, algunos autores afirman que dentro de la costumbre internacional si que tendrían cabida aquellos daños medioambientales que tienen una incidencia trasnacional(36).

(32) Doe v Unocal, 27 F Supp 2d 1174 (CD Cal 1998), US District Court for the Central District of California.

(33) AвAdie P., «A New Story of David and Goliath: The Alien Tort Claims Act Gives Victims of Environmental Injustice in the Developing World a Viable Claim Against Multinational Corporations», Golden Gate State University Law Review, Vol. 34, 2004, p. 746.

(34) Baenal v Freeport-McMoran Inc, 969 F Supp 362 (ED La 1997), US District Court for The Eastern District of Lousisiana.

(35) Aguinda v. Texaco, 142 F Supp 2d 534 (SDNY 2004), US District Court for the Southern District of New York.

(36) Cfr. JosePH, S., op. cit., pp. 29 y ss. 
De cuanto se lleva expuesto, podrían extraerse las siguientes conclusiones. La primera es que un espacio claro de consenso es aquel en el que el daño ambiente se vincula a delitos reconocidos por el derecho internacional (tortura, genocidio, esclavitud, trabajos forzados...). Un acuerdo de mínimos de la jurisprudencia reseñada es que ante graves atentados a los derechos humanos cesa la soberanía medioambiental, cimentada en la propiedad sobre los propios recursos. Un nivel menor de consenso, es el que existe cuando el daño, aun de considerables dimensiones, genera un grave riesgo para la vida o la salud de poblaciones enteras o que tengan carácter transfronterizo. De admitirse estos argumentos macro- y trans- (37) podrían servir también para justificar un recorte de la soberanía nacional e ir más allá en la construcción de un derecho penal del medioambiente internacional.

La propuesta de unir daño medio ambiental que tenga como base el núcleo más clásico e indiscutido de las normas del derecho penal internacional constituye el fundamento de un posible delito de ecocidio (38). Esta figura, que fue formulada por la doctrina a comienzo de los años 90 del pasado siglo, consiste en la causación de daños medioambientales dolosos con la intención de acabar con una etnia, raza o comunidad indígena. Un comportamiento prototípico de ecocidio sería el de la multinacional petrolera cuya explotación colisiona con los intereses de una pequeña comunidad indígena y que decide acabar con ella envenenando el agua potable.

El ecocidio, como crimen internacional, constituiría sobre todo una punta de lanza, que permitiría reclamar la competencia de la Corte penal internacional para estos asuntos y además plantear una reforma estratégica en el Estatuto de la Corte que permitiera superar la barrera Nüremberg, contemplando situaciones que van más allá de los comportamientos que se comenten en el contexto de una guerra o conflicto armado (39). La principal crítica no obstante que puede hacerse a la figura de ecocidio es que es poco realista. En primer lugar, por ser marcadamente intencional, los daños medioambientales deben estar dirigidos al exterminio de una comunidad, etnia o raza, y en segundo lugar, por exigir como finalidad el exterminio. Un delito de ecocidio imprudente que castigara el «exterminio imprudente» se acoplaría mucho más a la realidad. E igualmente estaría justificada una extensión del resultado, con el fin de contemplar los daños ecológicos efectuados con el fin por ejemplo de desplazar a una comunidad.

La idea de conectar la protección del medio ambiente con los ataques a los derechos humanos que tienen lugar durante guerras o conflictos armados (40), está ya presente en el Estatuto de la Corte Penal Internacional, cuyo artículo 8.2.b iv) considera crimen de guerra lanzar un ataque intencionadamente a sabiendas de que causará daños extensos, duraderos y graves al medio natural que sean claramente excesivos en relación con la ventaja militar que se pretenda conseguir. El carácter

(37) En general, sobre los delitos transnacionales y la necesidad de que sean objeto de atención por el derecho penal internacional, vid. CAO, L., «The Transnational and Subnational in Global Crimes», Berkely J. Int. L, 2004, p. 59; Sornarajah, M., «Transnational Crimes: The Third Limb of The Criminal Law», Singapore Journal of Legal Studies, 2004, pp. 390 y ss.

(38) Cfr. Gray, M., «The International Crime of Ecocide», California Western International Law Journal, Vol. 26, 1995-1996, pp. 215 y ss.

(39) Cfr. Sharp, P., «Prospects for Environmental Liability in the International Criminal Court», Virginia Environmental Law Journal, Vol. 18., 1999, pp. 217 y ss.

(40) Ampliamente sobre lo que sigue Matas, D., La protección del medio ambiente en el Derecho Internacional Humanitario, Tirant lo Blanch, Valencia, 2005. 
ponderable del medio ambiente, incluso cuando sus daños sean graves, extensos y duradero, resulta el aspecto más criticable de este precepto. Los efectos devastadores que los conflictos bélicos suelen tener para el medio ambiente aconsejarían eliminar esta posibilidad, que debiera completarse con la necesidad de testar medioambientalmente las armas de guerra, tal como se propone en la Red Cross Guidelines. Las deficiencias de la situación actual se pone de manifiesto, por ejemplo, en las resoluciones del Tribunal especial de Naciones Unidas para Ruanda, donde pese a los grandes daños ecológicos que ha producido este conflicto, no hay una sola mención al medio ambiente (41). El artículo 8.2.b iv del Estatuto resulta, sin embargo, absolutamente coherente con la opinión vertida por el Tribunal Internacional de Justicia en relación a la utilización del armamento nuclear. El Tribunal reconoce que más allá de la cuestión de si los tratados de protección al medio ambiente son de aplicación durante una guerra o un conflicto armado, resulta claro que estos tratados no han intentado privar a los Estados del ejercicio a la legítima defensa conforme al derecho internacional como consecuencia de su obligación de tutelar el medio ambiente. El Tribunal, en sintonía con el artículo 8.2 b iv, a lo único que obliga a los Estados es a tener en cuenta la protección del medio ambiente, debiendo evaluar si el daño resulta proporcionado y necesario para la consecución de un objetivo militarmente legítimo(42).

\section{DAÑOS CONTRA EL MEDIO AMBIENTE DE CARÁCTER TRANSNACIONAL: TRÁFICO ILÍCITOS Y DELITO ECOLÓGICO TRANSFRONTERIZO}

Que el derecho al medio ambiente no pueda encuadrarse entre los derechos humanos, no significa que no exista un derecho internacional del medio ambiente. El núcleo duro de este derecho es el que versa sobre daños que tienen carácter transfronterizos y también sobre «tráficos» vinculados con la protección de la naturaleza: el tráfico de especies protegidas, el tráfico con substancias peligrosas y el tráfico con residuos (43). Existen cientos de convenciones internacionales, bilaterales o multilaterales, que se ocupan de estos aspectos transnacionales.

Algunas de estas convenciones exigen incluso a los países parte la necesidad de establecer sanciones eficaces. Aun respetando un margen de apreciación nacional, que deja margen de maniobra al legislador nacional, la presencia del derecho penal en estos sectores es masiva. De este modo, puede decirse que en toda esta materia existe ya de facto una cierta armonización, sobre la que construir futuras infracciones comunes en materia de medio ambiente. Estas infracciones transfronterizas, podrían ir acompañadas de reglas de atribución de competencias de juris-

(41) Cfr. Drumbl, M., «Waging War Against the World: The Need to Move from War Crimes to Environmental Crimes», Fordham Int'l L. J., Vol. 22, 1998-1999, pp. 122 y ss; con referencia a los daños medioambientales de la Guerra del Golfo, SchwaвACH, A., «Ecocide and Geocide in Iraq», Colo. J. Int'l Envt. L. \& Pol., Vol. 15, 2004, pp. 1 y ss.

(42) Corte Internacional de Justicia, Legality of the Threat or Use of NuclearWeapons, Opinión Consultiva, I.C.J. Reports, 1996, p. 226

(43) Cfr. Roв, W., op. cit., pp. 276 y s. 
dicción que, sin llegar al principio de justicia universal, ampliasen notablemente el ámbito de las jurisdicciones nacionales.

Ejemplos de este incipiente derecho penal del medio ambiente armonizado es, por ejemplo, el Convenio internacional para prevenir la contaminación de buques (Marpol), cuya función es prohibir las descargas contaminantes de grandes petroleros, que exige de facto que sus infracciones sean castigadas penalmente por los Estados firmantes (art. 4.4). Igualmente a través de los delitos aduaneros, el contrabando o los delitos contra el medio ambiente los Estados miembros suelen dispensar ya una amplia protección a las especies protegidas, en cumplimiento del Convenio de Washington sobre el Comercio internacional de especies amenazadas de fauna y flora silvestres. E igual ocurre con el tráfico de residuos. La Convención sobre Contaminantes Orgánicos permanentes y sobre el artículo 4,3 del Convenio de Basilea sobre el Control de los movimientos transfronterizos de los desechos peligrosos y su eliminación obliga a los Estados firmantes a considerar delictivo el tráfico transfronterizo ilícito con desechos peligrosos.

El círculo de los delitos transfronterizos contra el medio ambiente podría cerrarse con una infracción en la que se sancionase la realización de vertidos, emisiones o introducción de sustancias o radiaciones ionizantes en el aire, suelo o agua que causara la muerte o una grave lesión, o un peligro concreto de estos resultados a una pluralidad de personas en un país distinto a aquel en el que se realiza la conducta típica. Esta infracción toma como modelo el artículo 2.1 a) del Consejo de Europa, que no requiere que el acto contaminante infrinja ninguna disposición administrativa, añadiendo el que el daño deba tener carácter transfronterizo (44).

Este precepto contiene una limitación del derecho de cada país a gestionar su medio ambiente que resulta aceptable de acuerdo con los principios del derecho penal internacional. En efecto, tras el caso Lotus, el Tribunal Permanente de Justicia penal entendió que los Estados tenían derecho a extender su ius puniendi a hechos realizados en el extranjero que lesionaran intereses no solo Estatales, sino también puramente individuales como la vida o la salud de sus ciudadanos. El límite a esta extensión del derecho penal de un Estado radicaba en la prohibición de abuso de derecho, que existe cuando el comportamiento que se pretende sancionar, resultaba lícito en el territorio en el que se realizó (identidad de la norma)(45). Como puede apreciarse, este es precisamente el problema que nos encontramos en los supuestos de delitos contra el medio ambiente, debido a su carácter accesorio. El comportamiento lesivo del medio ambiente que ocasiona el resultado de lesión o peligro de la vida o la salud de una pluralidad de personas en un país vecino, puede ser perfectamente lícito en el país donde se ha realizado como consecuencia del derecho de cada Estado a configurar su legislación medioambiental. Ahora bien, la existencia de un resultado de las características a las que se refiere el tipo penal propuesto hace a mi juicio que sea más que cuestionable señalar que en este caso existe un abuso de derecho. El Estado donde se ha realizado el comportamiento no puede utilizar su derecho al desarrollo y a la explotación de sus propios recursos,

(44) Sobre los daños transfronterizos en el derecho internacional del medio ambiente CALvo, L., op. cit., pp. 222 y ss. y 354 y ss. Desde el punto de vista penal, ver MARTIN, J., Strafbarkeit grenzüberschreitender Unweltbeeinträchtigungen,_Freiburg, 1989.

(45) Cfr. Jescheck, H., Tratado de Derecho penal, Vol. 1 (trad. Muñoz Conde/Mir Puig), Bosch, 1981, p. 228-229; SATZGER, H., Internationales und Europäisches Strafrecht, Nomos, 2010, p. 41. 
para justificar una normativa medioambiental que es capaz de generar daños o peligros masivos para un conjunto amplio de ciudadanos de otro Estado.

\section{MACRODAÑOS AMBIENTALES: EL DELITO DE GEOCIDIO}

En el derecho internacional existen algunas propuestas de infracciones internacionales, de diversa naturaleza jurídica, que versan sobre macrodaños ambientales. Un primer ensayo fue la inclusión de los supuestos de graves atentados contra el medio ambiente en el catálogo de crímenes internacionales. Pese a la denominación -international crime - esta figura no se refiere a una responsabilidad penal. La finalidad de los crímenes internacionales, en el derecho internacional público, consistía en establecer un régimen de responsabilidad especial de los Estados con el fin de indemnizar a terceros. En la actualidad el derecho internacional ha abandonado la pretensión de crear esta categoría «especial» de responsabilidad estatal que tuvo su apogeo con el artículo 19 de los Draft Articles on State Responsability que en 1991 realizo la ILC. Concretamente, el artículo 19.2 consideraba un crimen internacional «a serious breach of an international obligation of essential importance for the safeguarding and preservation of the human environment, such as those prohibiting massive pollution of the atmosphere or of the seas» (46).

En el ámbito específico del derecho penal internacional el proyecto más importante es el Draft Code o Crimes Against the Peace and Security of Mankind, que tuvo como finalidad la extensión de los delitos de derecho internacional más allá de los previstos en la Carta de Nüremberg. El artículo 26 del Draft Code contiene una infracción denominada «daños intencionales y graves al medio ambiente», que sanciona a «quien de intencionadamente cause o ordene la causación de un daño al medio ambiente grave, duradero y extendido (47). El problema del medio ambiente, como interés tutelado por los delitos contra la paz y seguridad, es que no tiene substantividad propia. Por esta razón, el artículo 26 fue objeto de numerosas críticas en el seno de la ILC con el argumento de que el medio ambiente no guardaba relación con la paz y seguridad, salvo que se trate de daños intencionales extraordinariamente graves realizados por ejemplo por grupos terroristas. En este caso, se indicaba, bastaría con la tipificación de los crímenes de guerra que hoy figura en el Estatuto de la Corte Penal internacional, y al que anteriormente nos referíamos.

En la doctrina son varios las propuestas de configurar un delito de geocidio, cuyo interés tutelado sería específicamente el medio ambiente (48). Las propuestas pivotan sobre tres elementos (a) un comportamiento doloso o negligente, (b) que

(46) Abandonada esta categoría de los crímenes internacionales, el proyecto de artículos sobre la responsabilidad del Estado por hechos internacionalmente ilícitos de 2001 incluye la responsabilidad de los estados por daños al medioambiente como un supuesto más; vid. el artículo 31 y sus comentarios, en: Comisión de Derecho Internacional, Draft articles on Responsibility of States for Internationally Wrongful Acts with commentaries, pp. 62 y ss. (en http://untreaty.un.org/ilc/texts/instruments/ english/commentaries/9_6_2001.pdf)

(47) Artículo 26: «An individual who wilfully causes or orders the causing of widespread, long-term and severe damage to the natural environment shall, on conviction thereof, be sentenced [to ... . .»

(48) Cfr. Berat, L., «Defending the Right to a Healthy Environtment: Toward a Crime of Geocide in International Law», Boston University International Law Journal, Vol. 11, 1993, pp. 327 y ss. 
ocasione un daño ecológico grave, extenso y perdurable, (c) que tenga consecuencias internacionales y (d) que sea además injustificado. Esta propuesta destaca no sólo la ampliación del tipo subjetivo, lo que resulta razonable teniendo en cuanta la naturaleza de los daños medioambientales, sino por la adicción de dos requisitos adicionales como son las consecuencias internacionales y el carácter injustificado del daño. Las consecuencias internacionales van más allá de los daños transfronterizo. Su idea es la de daños medioambientales que afectan a la comunidad internacional en su conjunto, aunque se produzcan en el territorio de un país, cuyo prototipo podrían ser desastres de la magnitud del causado por el petrolero Exxon Valdes o Chernobil o el reciente vertido de British Petroleum en el golfo de Méjico. El carácter innecesario del mal es el equivalente al carácter ilícito de las conductas prohibidas por los delitos ecológicos nacionales. Innecesario equivaldría a irracional en cuanto que carece de cualquier tipo de justificación económica o social, porque existían alternativas razonables para conseguir estos objetivos.

\section{MEDIO AMBIENTE Y EXPOLIACIÓN DE RECURSOS NATURALES: EL PATRIMONICIDIO}

Algunos de los supuestos de daños medioambientales que se han sometido a la jurisdicción norteamericana, en el marco del ATCA, podían haber sido también contemplados desde la óptica de los derechos de los pueblos indígenas y del denominado genocidio cultural. Este sería el caso, por ejemplo, de Aquinda v. Texaco se vertieron miles de galones de petróleo y otros productos tóxicos, que acabó por expulsar de sus territorios ancestrales a poblaciones indígenas. El Proyecto de Naciones Unidas de Declaración de los Derechos de los pueblos indígenas define el genocidio cultural o ethnocidio en términos que expresan muy bien el contenido de injusto de este tipo de comportamientos: «cualquier acción que tenga como intención o como efecto la desposeerlos de sus tierras o sus recursos». El problema del genocidio cultural como aproximación al medio ambiente es similar al que hemos constatado anteriormente: El daño contra el medio ambiente es el mecanismo para lesionar el interés tutelado en el genocidio cultural, pero sigue sin tener carácter autónomo.

No obstante, esta infracción evidencia un aspecto muy importante de los daños medioambientales, la protección del medio ambiente como patrimonio de un país sobre el cual se ejercen precisamente sus derechos a la autodeterminación, preservándolo de actos de expoliación. El derecho a la autodeterminación incluye la soberanía permanente sobre los propios recursos y las riquezas naturales. Tras un largo camino que comienza tras la creación de Naciones Unidas, la Resolución 2158 titulada «Soberanía permanente sobre los propios recursos» plasmó este derecho de los pueblos y las naciones, y que después se plasmó en la Carta de Derechos y Deberes Económicos de los Estados (artículo 2) y el Carta Africana de los Derechos Humanos y de los Pueblos. De este modo, no cabe duda de que este derecho constituye un principio básico del derecho internacional. En todos estos 
textos se remarca además de manera especial que este derecho tiene derecho a ejercerse frente a empresas multinacionales (49).

Existen algunas propuestas doctrinales cuya función es tutelar este derecho a través de la creación de una figura delictiva de carácter internacional a la que denominan expolio económico o patrimonicidio y que definen como acto ilegal de depredación cometido por el legislador, funcionarios públicos o individuos. Aunque la conducta típica de esta figura dista mucho de estar definida (depredación), su injusto revela un importante salto cualitativo en relación por ejemplo a delitos como los de corrupción, malversación o enriquecimiento ilícito que aparecen en la Convención de Naciones Unidas contra la corrupción. Lo que caracterizaría al comportamiento típico de este delito es que resulta idónea para destruir los fundamentos económicos de una sociedad (50).

Igualmente resulta de gran interés la delimitación del círculo de los posibles autores del delito, que abarca tanto a individuos, es decir, dirigentes de empresas multinacionales, como a los gobernantes y altos funcionarios nacionales. Esta conjunción expresa muy bien la esencia del delito: la corrupción a gran escala por parte de los dirigentes de un país, con el fin por ejemplo de poner sus recursos naturales en manos de empresas multinacionales, a través de concesiones o actos legislativos que hacen legal la explotación abusiva de estos recursos, sin que de ello redunden beneficios substanciales para los ciudadanos de dicho Estado. Con ello el delito de patrimonicidio serviría para «cerrar el círculo». Tal como habíamos indicado, el problema de la protección internacional del medio ambiente es la soberanía de los Estados sobre sus propios recursos y su derecho al desarrollo. Esta soberanía hace complejo la fijación de estándares comunes, en cuanto que presupone un derecho a ponderar autónomamente el interés medio ambiente, de un lado, y el derecho al crecimiento económico y al desarrollo, de otro. El patrimonicidio representaría, precisamente, un abuso intolerable de este derecho de ponderación por parte de los gobernantes del país, a su propio favor y en el de las empresas nacionales. El patrimonicidio serviría para sancionar los daños medioambientales legales (51).

\section{ALGUNAS CONCLUSIONES SOBRE LA TIPIFICACIÓN DE LAS INFRACCIONES DEL DERECHO PENAL INTERNACIONAL DEL MEDIO AMBIENTE}

Este breve repaso a las diversas propuestas de delitos internacionales contra el medio ambiente, ha puesto de manifiesto que existen cinco aproximaciones diferentes a la hora de tipificar estos delitos:

- El ecocidio en el cual el daño al medio ambiente sería el instrumento para exterminar a una raza o etnia o, partiendo de la propuesta de genocidio cultural,

(49) Ampliamente, ver: Kofele-Kale, N., The International Law of Responsibility for Economic Crimes, 2. a ed., Ashgate, 2006, pp. 79 y ss.

(50) Ibíd., pp. 9 y ss.

(51) Ibíd., pp. 259 y ss. 
para privar a una comunidad indígena de su identidad étnica, cultural o provocar su desplazamiento forzoso.

- El geocidio que comprendería daños al medio ambiente extendidos y duraderos, realizados dolosa o negligentemente, realizados sin justificación económica o social alguna, y que por su magnitud tuvieran una dimensión internacional.

- El patrimonicidio que se referiría, además de a otras conductas, a la expoliación de los recursos naturales como consecuencia de actos de abuso de poder, ya sea de los dirigentes de un país o de empresas multinacionales.

- Los delitos de tráficos ilícitos relacionados con el medio ambiente y que tendrían por objeto los residuos, especies protegidas y substancias peligrosas.

- El delito ecológico transfronterizo grave que abarcaría aquellos supuestos en los que el daño al medio ambiente afecta, ya sea mediante una lesión o un peligro concreto, gravemente a la salud o la vida de una pluralidad de personas en otro país.

Dentro de este conjunto de infracciones tendría sentido el que los delitos de ecocidio, geocidio y patrimonicidio se sometieran al principio de justicia universal y que sobre ellos tuviera competencias la Corte Penal Internacional o un tribunal medioambiental internacional, especializado transversalmente en el derecho internacional del medio ambiente. Recientemente los relatores de Naciones Unidas sobre tortura y derechos humanos han propuesto un tribunal internacional que se ocupara de juzgar a empresas multinacionales y que podría ocuparse igualmente del enjuiciamiento de este tipo de delitos.

Las infracciones de tráficos ilícitos o el delito ecológico transfronterizo, que operarían como derecho penal internacional armonizado, podrían ser juzgados de acuerdo con el principio de territorialidad y el de personalidad activa de forma tal que tuvieran también jurisdicción el Estado miembro de nacionalidad o residencia de los autores del delito o si se admite la responsabilidad colectiva, tal como se propondrá a continuación, del país donde tiene su sede social, la persona jurídica que ha cometido la infracción o la empresa madre.

Este conjunto de infracciones tienen como principal defecto el que aún es necesario una gran labor para conseguir una formulación de las mismas que se acomode al principio de determinación de la ley penal. Solo los tráficos ilícitos relacionados con el medio ambiente y el delito ecológico transfronterizo grado tienen un grado de precisión suficientes. No obstante, estos cinco vectores diferentes muestran el camino de un futuro derecho penal internacional del medio ambiente.

\section{LOS RESPONSABLES: LA RESPONSABILIDAD PENAL DE LAS MULTINACIONALES}

\section{LA RESPONSABILIDAD PENAL DE LAS PERSONAS JURÍDICAS EN EL DERECHO INTERNACIONAL}

El segundo pilar del derecho penal del medio ambiente debe ser la responsabilidad de las corporaciones, un hecho que aun resulta discutido dentro del derecho 
internacional, pero que en esta materia resulta imprescindible para contar con un derecho penal eficaz.

Como es bien conocido, el derecho internacional generaba originariamente derechos, obligaciones y sanciones únicamente para los Estados. Uno de los avances más significativos de los procesos de Nüremberg fue el que por primera vez los individuos como tales se consideraron también como sujetos de derecho internacional. En Nüremberg, no obstante, se inició una ambigua doctrina en relación a en qué medida las corporaciones o las personas jurídicas resultaban también responsables de delitos como el genocidio o los crímenes de guerra. De un lado, en algunas de las decisiones más importantes se habla con claridad de corporaciones o empresas criminales, para referirse a las SS o a IG Farben, multinacional que proporcionó el gas de los campos de concentración y utilizó como esclavos a muchos judíos, pero de otro, en Nüremberg no hubo ninguna condena contra las personas jurídicas, sino tan sólo a directivos o a personas pertenecientes a dichas organizaciones. Es más, en US v. Goering expresamente se indica que «Crimes against international law are committed by men, not by abstract entities, and only by punishing individuals who commit such crimes can the provisions of international law be enforced.» (52). Las alusiones a empresas criminales dentro de los juicios de Nüremberg no tuvieron otro significado que hacer más fácil el procesamiento de sus miembros, pero para la mayoría de la doctrina la responsabilidad por los delitos que se juzgaron en Nüremberg exigían, por su extrema gravedad, la constatación de un reproche moral que no podía ser efectuado contra las corporaciones.

Este estado de cosas ha pervivido en los instrumentos internacionales y en la práctica de los tribunales internacionales que se han ocupado de los delitos tradicionales del derecho internacional. En efecto, ni las convenciones sobre el genocidio o la tortura, ni las resoluciones de Naciones Unidas que han creado los tribunales especiales de Ruanda o la ex Yugoslavia han incluido la responsabilidad penal de las personas jurídicas. Como tampoco lo ha hecho el Tratado de Roma que ha creado la Corte Penal Internacional, donde expresamente se rechazó la propuesta del gobierno francés solicitando la introducción de la responsabilidad de las corporaciones.

Ante esta situación no es de extrañar que el Tribunal de Apelaciones del Segundo Circuito, de los Estados Unidos, en un supuesto de enorme transcendencia relativo a la Allien Tort Claim Act, Kobel v. Royal Dutch(53), haya considerado que la responsabilidad penal de las personas jurídicas no forma parte de la «law of nations», es decir, de la costumbre internacional. De este modo ha rechazado la demanda interpuesta contra la petrolera holandesa y sus filiales por complicidad en crímenes contra la humanidad cometidos por el Gobierno de Nigeria. La sentencia resulta sorprendente porque, como ya se señaló anteriormente, desde el asunto Doe v. Unocal aparentemente se admitía de forma pacífica que las corporaciones podían ser hechas responsables bajo la ATCA(54). De hecho este asunto ha sido el prime-

(52) Int'1 Military Trib. at Nuremberg, United States v. Goering, 6 F.R.D. 69, 110

(53) Kiobel v. Royal Dutch Petrolium Co, 621, F 3 ed 111, (2010), United States Court of Appeals, Second Circuit, de gran utilidad la lectura del voto particular del Juez Leval a la sentencia.

(54) La última decisión antes de Kiobel, sancionando a una persona jurídica fue Presbyterian Church of Sudan v. Talisman Energy, Inc., 582 F.3d 244, 261 n. 12 (2d Cir.2009). No obstante, para la corte el hecho de que hubiese decisiones anteriores, no significaba que hubiese jurisprudencia al res- 
ro en el que una empresa ha alegado en su defensa que la responsabilidad de las personas jurídicas, no formaba para del ius cogens internacional y que por tanto no podía ser admitida dentro de un texto legal en el que tanto las infracciones, como las personas que pueden ser hechas responsables de las mismas tienen que ser determinadas conforme a este derecho.

Aunque en el marco del Estatuto de la Corte pudo resultar comprensible rechazar la responsabilidad de las personas jurídicas, porque ello implicaba abordar un asunto sobre el que no existe consenso en los derechos internos, como es la sanción de partidos políticos o movimientos independentistas, el derecho penal internacional del medio ambiente no puede, sin embargo, tener el mismo punto de partida. Y ello por varias razones (55). Primera, porque como desde hace tiempo se ha encargado de poner de manifiesto la Ciencia Política (56) y una buena parte de la doctrina del derecho internacional (57), las sociedades multinacionales son hoy verdaderos actores políticos del mundo globalizado, con mayor poder de influencia y poder que el de muchos Estados. Este nuevo estado de cosas hace que resulte necesaria superar la ambigua noción de «corporate complicity» que se utiliza en el derecho internacional y que, desde los tiempos de Nüremberg, se utiliza para designar la implicación de las grandes corporaciones en la violación de derechos humanos. Segundo, porque de hecho el derecho penal internacional ha abandonado el societas delinquere non potest. La última generación de convenios internacionales, tanto de Naciones Unidas, como de la OCDE o de la Unión Europea impulsan la responsabilidad de las personas jurídicas, hasta el punto de que han sido el detonante de que muchas legislaciones nacionales hayan abandonado el viejo dogma. Tercera, por razones de eficacia. Como se expuso anteriormente, un derecho penal internacional del medio ambiente que no contemple la responsabilidad colectiva sería tremendamente ineficaz e injusto. Lejos de sancionar a los dirigentes de la sociedad matriz acabaría descargando todo su potencial sobre técnicos y directivos locales, con escaso poder de decisión. Cuarta, porque las propias empresas multinacionales a través de la autorregulación plasmada en sus Códigos Éticos se autoproclaman ciudadanos responsables de evitar la comisión de delitos de corrupción, el medio ambiente o las infracciones a los derechos humanos (58).

pecto, en cuanto que no había existido nunca un pronunciamiento expreso del tribunal sobre esta cuestión. El TS de los Estados Unidos, en su decisión de 27-10-2011, ha admitido el recurso de certiorari con el fin de pronunciarse sobre esta cuestión.

(55) Con carácter general para todo tipo de violaciones a los derechos humanos, vid. BAIGúN, D., «El Estatuto de Roma y la responsabilidad penal de las personas jurídicas», en Libro Homenaje al Prof. Marino Barbero Santos, Vol. I, Ed. de la Universidad de Castilla la Mancha, Cuenca, 2001, p. 85 y ss; Nieto Martín, A., «Autorregulación, compliance y Justicia restaurativa», en Arroyo Jiménez, L. A. y Nieto Martín, A. (coords.), Autorregulación y sanciones, Lex Nova, Valladolid, 2008, pp. 113 ss; RATner, S., «Corporations and Human Rights: A Theory of Legal Responsibility», The Yale Law Journal, Vol. 111, 2001, pp. 443 y ss.

(56) Vid. Fuchs, D., Business Power in Global Governance, Lynne Riener Publishers, 2007.

(57) Vid. Entre otras muchas posibles referencias: Special Representative of the UN SecretaryGeneral on business and human rights (SRSG), Geneva, Dec. 4-5, 2007; Human Rights Watch, On the Margins of Profit, vol. 20, núm. 3, febrero 2008; Kalas, P., «International Environmental Dispute Resolution and the Need for Access by Non Sate Entities», Colo. J. Int.'l Envtl. L. \& Pol, Vol. 21, 2001, pp. 191 y ss.

(58) Vid. ampliamente sobre este argumento: Eutenier, G., «Towards a Corporate Law of Nations, Multinational Enterprises Contribution to Customary International Law», Tulane Law Review, vol. 82, 2007-2008, pp. 757 y ss. 
La eficacia de la responsabilidad colectiva responde a uno de los principios básicos de la teoría de la organización empresarial: la mejor forma de controlar a un directivo es hacer responsable de lo que en él ocurra a sus dirigentes. Los socios de una empresa que ha recibido fuertes sanciones penales -multas, intervención judicial, interdicción de participar en contrataciones públicas-e incluso ha experimentado pérdidas como consecuencia de los daños reputacionales que le ha ocasionado el proceso penal, exigirán de sus administradores que implemente controles eficaces que ayuden a prevenir y descubrir los comportamientos delictivos que se han cometido en su interior.

La responsabilidad de las personas jurídicas, como epicentro del derecho penal internacional del medio ambiente, tiene otra importante ventaja y es que sirve para garantizar la efectividad del arsenal de normas de autorregulación que las empresas han adoptado como consecuencia de la estrategia de control que hasta ahora han seguido las organizaciones internacionales. En efecto, los Códigos éticos, declaraciones de responsabilidad social corporativa o otros instrumentos de autorregulación similares hasta ahora no son sino meras declaraciones de intenciones, con escasa transcendencia práctica y que responden en buena medida a necesidades de marketing. La responsabilidad penal colectiva garantizaría la accountability, ante los tribunales de justicia, de las grandes empresas por sus normas de autorregulación.

Para que la responsabilidad penal de las personas jurídicas cumpla estos objetivos es necesario establecer un sistema de imputación eficaz y diseñar una estrategia que permita además localizar en la medida de lo posible la infracción delictiva en la empresa matriz, otorgando, en la medida de lo posible, la competencia a la jurisdicción penal del Estado donde tiene su sede social o principal centro de negocios.

\section{EL SISTEMA DE IMPUTACIÓN: LA CULPABILIDAD DE EMPRESA}

Como es bien conocido existen dos grandes sistema de imputación, en el marco de la responsabilidad colectiva. El primero de ellos, que procede del derecho civil, traslada a la empresa el comportamiento realizado por uno de sus empleados, o en alguna de las versiones, solo de su personal dirigente. El segundo modelo de imputación busca la responsabilidad de la empresa en un defecto de organización propio que es el que precisamente ha motivado la aparición del comportamiento delictivo(59).

Este sistema empieza a imponerse en numerosos ordenamientos nacionales, entre ellos varios de la UE, es preferible por razones constitucionales y también por razones de eficacia. Es preferible por razones constitucionales porque aplica a las personas jurídicas el principio de culpabilidad, que en muchos países tienen rango constitucional. El modelo vicarial de imputación constituye desde el punto de vista de la empresa un supuesto de responsabilidad objetiva. En cuanto que nada puede hacer para desvincularse del comportamiento delictivo que ha realizado alguno de sus agentes, y ello aunque esta empresa se haya esforzado eficazmente en prevenirlo. Pero sobre todo este modelo es preferible por sus mejores rendimientos prácticos. El sistema vicarial de responsabilidad, sobre todo, cuando se exige que la persona

(59) En lo que sigue, Nieto Martín, A., La responsabilidad penal de las personas jurídicas: un modelo legislativo, Iustel, 2009, pp. 85 y ss. 
natural que ha realizado el delito sea un dirigente o alto directivo, favorece a las grandes empresas y perjudica enormemente a las pequeñas. En estas el sistema de dirección, mucho más centralizado y menos complejo, permite con relativa facilidad la imputación de los dirigentes, sobre todo en aquellos delitos como son los medioambientales, que admiten la modalidad imprudente. Dado que nuestro objetivo, son las grandes empresas el modelo vicarial sería tremendamente disfuncional.

El sistema vicarial provoca igualmente que las corporaciones intenten ocultar por todos los medios el delito que se ha cometido en su interior, adoptando una actitud de obstrucción a la investigación judicial o administrativa. La empresa sabe que su suerte está unida al del responsable individual, por eso no tiene otra defensa posible que cooperar con él para que su infracción no sea descubierta. El modelo vicarial, finalmente, desincentiva la autorregulación de la propia entidad, con el fin de evitar, y sobre todo descubrir, los comportamientos delictivos que se realizan en su interior. Si el derecho sancionador no reconoce los esfuerzos que la empresa ha realizado para cumplir con el ordenamiento jurídico, y trata igual a las empresas que han sido diligentes, que a las que han descuidado los aspectos preventivos, es normal que las primeras se replanten la asignación de los recursos destinados a su sistema de compliance.

En el marco del derecho penal internacional del medio ambiente un sistema basado en la responsabilidad propia de la empresa tendría como principal virtud el que reforzaría los sistemas de autorregulación ya existentes. Esto es, hasta ahora la estrategia de las multinacionales ha consistido en utilizar toda su influencia y poder para que en buena medida se delegue en su capacidad de organización interna la protección del medio ambiente. Las organizaciones internacionales han aceptado esta estrategia apostando por la responsabilidad social corporativa y los instrumentos de autorregulación interna. Son conocidas en este sentido las Líneas Directrices para Empresas Multinacionales de la OCDE donde se «enuncian principios y normas voluntarias para una conducta empresarial responsable compatible con las legislaciones aplicables», e igual estrategia es la emprendida por Naciones Unidas, donde el Consejo Económico Social y Cultural a través de las Normas sobre responsabilidad de corporaciones transnacionales en relación a los derechos humanos pretende también colocar en el terreno del voluntarismo y la autorregulación el control de las conductas desviadas generadas por la actividad empresarial (60).

Esta estrategia que bien puede interpretarse como una victoria del poder económico, que hábilmente evita la regulación, puede ser aprovechada, en sentido inverso, a través de la responsabilidad penal colectiva. Pues de lo que se trata básicamente, cuando se produzca un daño al medio ambiente, es permitir que el juez penal inspeccione si todo este sistema autorregulador era verdaderamente efectivo o resultaba simplemente cosmética publicitaria. La responsabilidad colectiva, basada en la culpabilidad de empresa, constituye una estrategia basada en una autorregulación coaccionada y supervisada.

Un problema ulterior, que aquí no puede abordarse con detalle, afectaría a la génesis de la propia normativa de autorregulación. Uno de los defectos que se le atribuyen a este sistema de imputación es que resulta bastante impreciso: ¿en qué consis-

(60) Vid. Naciones Unidas, Consejo Económico y Social, «Norms on the responsibilities of transnational corporations and other bussines enterprises with regard to Human Rights», 26 de agosto de 2003 . 
te un buen compliance program de prevención de delito medioambientales? (61) Esta imprecisión es un arma de doble filo. De un lado, una justicia penal en exceso exigente siempre puede condenar a las empresas indicando que eran precisos aún más controles y medidas de organización interna, pero de otro, una buena defensa de la corporación también puede explotar esta ambigüedad para convencer a los órganos de inspección o de persecución penal, sin grandes conocimientos en este punto, de que su sistema era el adecuado y que la explicación del comportamiento delictivo se encuentra en la torpeza de un técnico o directivo (reverse whistleblowing)(62).

No obstante, al menos en materia de medio ambiente, existe ya un grado de estandarización acerca de lo que constituye una buena organización interna, con normas ISO muy concretas. Por otro lado, este problema podía evitarse si la legislación internacional del medio ambiente concretara aun más este proceso de estandarización, lo que debería abarcar necesariamente la regulación no sólo de los contenidos, sino también de los procesos internos de toma de decisiones de las empresas a la hora de fijar estos estándares. Un proceso legislativo interno, dentro de la empresa, abierto y trasparente donde tomarán parte los diversos stakeholders afectados por la actividad empresarial legitimaría la normativa de autorregulación y, en lo que al aspecto penal se refiere, la haría más fuerte ante el juez penal. Como puede apreciarse, la responsabilidad de las personas jurídicas no es sino el reflejo penal de los dos movimientos más importantes que en las últimas décadas se han producido en la gestión empresarial: la responsabilidad social corporativa y la corporate governance.

\section{LAS INFRACCIONES: EL DEFECTO DE ORGANIZACIÓN COMO INFRACCIÓN AUTÓNOMA Y LA TRANSPARENCIA EN LA RESPONSABILIDAD SOCIAL CORPORATIVA}

Tener un buen sistema de imputación es una condición necesaria para un sistema de responsabilidad de personas jurídicas eficaz, pero no es la única condición, sobre todo cuando se trata de empresas multinacionales. Si el sistema penal establece como sujetos responsables a las personas jurídicas, la existencia de un grupo de sociedades servirá para hacer mucho más compleja la responsabilidad de la persona jurídica matriz. Por otro lado, debe idearse un conjunto de infracciones que permitan accionar el proceso penal no sólo en el país en donde los hechos han tenido lugar, sino también en el lugar donde se ubica la empresa matriz. Un proceso penal contra la persona jurídica matriz que se desarrolla en un país con un sistema judicial débil encontraría numerosos obstáculos, y además tendría que depender de un sistema de cooperación judicial que hasta ahora está diseñado en exclusiva para las personas naturales, y que apenas si contiene disposiciones relativas a la cooperación judicial en procesos donde las imputadas sean entidades colectivas.

Desde hace ya bastantes años el derecho sancionador de la competencia de la UE ofrece una solución interesante para afrontar la responsabilidad de los gru-

(61) Cfr. Nieto Martín, A., La responsabilidad penal de las personas jurídicas, op. cit., pp. 215 y ss.

(62) Ibíd., pp. 199 y ss. 
pos de empresas: el concepto de unidad económica (63). Como es conocido a través de este concepto el TJUE y la Comisión trasladan el centro de imputación de la persona jurídica, donde se ha realizado la infracción, a la empresa matriz, en aquellos grupos en los que existe una dirección unitaria y se demuestra que la empresa matriz ha tenido un influjo decisivo en las prácticas sancionadas. Estos elementos permiten considerar que el centro de imputación es la empresa y no las personas jurídicas que en concreto las componen. En algunos supuestos se ha llegado incluso a apuntar que la persona jurídica matriz tiene un deber de evitar los ilícitos cometidos por la filial, por lo que no sería preciso demostrar que ha existido una intervención directa en el acuerdo. Esta última tendencia se corresponde con lo que ocurre en las grandes empresas multinacionales, donde las políticas de compliance son políticas transversales o de grupo diseñadas por la empresa matriz, a través de un comité de ética del grupo o de un Chief Ethic Officer que después tiene delegados en todos los países, donde la empresa desarrolla su actividad(64).

El concepto de unidad económica solucionaría el que la empresa matriz pudiera ser imputada en el proceso penal del país donde se ha realizado el delito ecológico por alguno de sus agentes. Pero como antes indicaba, esta posibilidad no es suficiente cuando este país posee un sistema judicial débil o va a encontrarse con problemas de cooperación judicial del estado donde la matriz tiene su sede. Este problema estaría solucionado si se contara con infracciones de derecho penal internacional, como las que antes se proponía, sometidas al principio de justicia universal o que recogieran el principio de personalidad activa, permitiendo la jurisdicción en el país donde la sociedad tiene su sede o principal centro de actividad. Más al día de hoy, no es esta la situación, por lo que es preciso diseñar infracciones que trasladen el locus comissi delicti al sistema judicial de la sociedad matriz.

En este punto existen dos posibilidades. La primera estrategia sería una combinación entre el principio de personalidad activa, del lado del derecho penal, y la decisión de los Estados de aplicar a sus empresas multinacionales la legislación medioambiental nacional. De este modo, los tipos penales en blanco del derecho penal nacional resultarían también de aplicación. Esta solución resulta coherente con una propuesta que desde hace décadas viene manteniéndose por algunos autores del derecho internacional del medio ambiente, tendente a aplicar la legislación administrativa nacional a sus empresas con independencia del país en el que actúen (65).

Desde el punto de vista del derecho internacional, la aplicación del principio de personalidad activa, sin necesidad del requisito de la doble incriminación constituiría una novedad relativa. Esta forma de proceder resulta, en efecto, similar a la que opera en el Convenio OCDE sobre corrupción de funcionarios públicos internacionales, en la que opera el principio de personalidad activa y se sancionan los actos de corrupción de funcionarios públicos extranjeros con independencia de si los hechos son constitutivos de delito o se persiguen en el país de origen del funcionario. Ahora bien, el Convenio OCDE sigue aplicando el principio de territoria-

(63) Vid. Nieto Martín, A., Fraudes Comunitarios: Derecho penal económico europeo, Praxis, Barcelona, 1996, p. 216.

(64) Vid. Moosmayer, K., Compliance: Praxisleitfaden für Unternhemen, Beck, München, 2010, pp. 31 y ss.

(65) Cfr. Morimoto, T., op. cit., passim 
lidad, aunque entendido, eso sí, de manera muy amplia. Es necesario que la propuesta o el pacto corrupto tengan lugar al menos parcialmente en el Estado que reclama la jurisdicción(66).

Con independencia de si es el derecho internacional, permitiría en abstracto la sanción de comportamientos lícitos que se realizan en el territorio de otro país, lo que es cierto es que en la praxis los problemas de cooperación serían enormes. Aunque las víctimas se decidieran a denunciar los atentados al medio ambiente en el país de origen de la empresa multinacional, el estado del país donde se realizan los hechos pondrían normalmente numerosos obstáculos para cooperar en un proceso penal que puede entender atenta contra su soberanía.

Estos problemas, prácticos y teóricos, pueden solventarse si en lugar de sancionar directamente el daño medioambiental, el derecho del país de origen de la multinacional sanciona la carencia de un sistema de autorregulación eficaz que prevenga daños medioambientales. Dado que la implantación de este sistema corresponde a la empresa matriz la infracción se entendería cometida en su territorio.

Una estrategia muy similar, que solo algunos años podría parecer utópica, es la que ha acogido recientemente la Bribery Act en el Reino Unido y que ha entrado en vigor el 1 de julio de 2012. La Sección 7 de esta norma ha creado una infracción propia de la persona jurídica denominada expresamente «fallo de la organización comercial para prevenir la corrupción», en el que considera responsable a la persona jurídica cuando una persona de la organización ha cometido un delito de corrupción con el fin de obtener o retener negocios, salvo que la persona jurídica pruebe que ha implementado procedimientos adecuados para prevenir al realización de este tipo de comportamientos. Como puede verse, y dejando de lado que la existencia de medidas de prevención se considera una defense, lo cierto es que el defecto de organización constituye el injusto esencial de esta infracción. De hecho la ley no ha entrado en vigor hasta que el Secretario de Estado no ha publicado unas guidelines que indican a las empresas que procedimientos deben implementar para prever la corrupción(67). Mas lo novedoso no es sólo la adopción de este modelo de imputación, sino la configuración de los criterios de aplicación de la ley penal en el espacio que se establecen específicamente para esta infracción. Los tribunales del Reino Unido resultan competentes para sanciones, como multas ilimitadas, cualquier acto de corrupción cometido en el extranjero por una organización comercial que realice una parte substancial de sus negocios en el territorio del Reino Unido (68). Aunque bajo la apariencia del principio de personalidad activa, la Bribery Act se ha instaurado de facto un principio de justicia universal para las grandes multinacionales, en cuanto la mayor parte de estas empresas realizan negocios en el Reino Unido. El lugar de residencia que a veces se utiliza en el marco del principio de personalidad activa, transformado, en el caso de las personas jurídicas, en el lugar en el que se realizan negocios de

(66) FABIÁn CAPARRós, E., La corrupción de agente público extranjero e internacional, Tirant lo Blanch, 2003, p. 146.

(67) Ministry of Justice, The Bribery Act 2010: Guidance about procedures which relevant comercial organisations can put into place to prevent persons associated with them from bribing (section 9 of the Bribery Act 2010), 2011 (disponible en: http://www.justice.gov.uk/downloads/legislation/ bribery-act-2010-guidance.pdf).

(68) Secciones 7 (5) y 12 (5). 
manera substancial, conlleva en la práctica una ampliación más que notable de los principios de aplicación de la ley penal en el espacio. A los efectos que interesan para el futuro diseño de un derecho penal internacional del medio ambiente, la Bribery Act constituye un excelente ejemplo de lo eficaz que resulta la combinación del criterio de defecto de organización, combinado con la aplicación extraterritorial del derecho penal.

Ahora bien, de acuerdo con la propuesta aquí defendida en realidad no sería ni tan siquiera necesario la utilización de la idea de extraterritorialidad en cuanto podía entenderse sin más que el defecto de organización se ha cometido, territorialmente, en este caso, en el Reino Unido. Esta propuesta no es absolutamente desconocida. La regulación del mercado de valores, del blanqueo de capitales, de la protección de datos personales o de la salud de los trabajadores contienen ya en muchos países infracciones penales o administrativas donde se sanciona el no contar con un sistema de prevención eficaz destinado a prevenir estos comportamientos delictivos o riesgos. Allí donde el derecho administrativo a través de lo que se ha dado en llamar la autorregulación regulada, impone a las empresas la adopción de sistemas de prevención internos, suele aparecer una infracción que castiga ya la mera ausencia de este sistema de autorregulación, con independencia de si se ha producido un comportamiento delictivo (69).

La sanción de la falta de organización de la empresa resultaría incluso coherente, en el marco de un delito de resultado de lesión o peligro, con el principio de ubicuidad, que determina cuando un hecho delictivo se realiza en el territorio de un Estado. De acuerdo con la teoría de la ubicuidad, de aparecer el comportamiento delictivo en el país $X$, en cuanto que el defecto de organización de la empresa se ha producido en el país donde tiene su sede Y, podría mantenerse razonablemente la jurisdicción de este último Estado, porque aunque el resultado típico no se ha producido en él, si que el comportamiento típico de la empresa ha tenido lugar en su territorio. Este argumento sería mucho más difícil de mantener si el modelo de imputación que se adopta es el vicarial. De acuerdo con este sistema la persona jurídica no tiene culpabilidad propia, sino que se le da traslado del comportamiento infractor de su agente. Conforme al modelo de responsabilidad por defecto de organización que aquí se propone, existen dos culpabilidades distintas y dos comportamientos distintos, el colectivo y el individual.

Una segunda forma de trasladar la competencia jurisdiccional al país sede de la empresa matriz descansa en la protección de la corporate social transparency. Las páginas web de las industrias energéticas o de las grandes constructoras contienen numerosa publicidad medioambiental. Cada vez son más las empresas que publican informes de sostenibilidad o en su informe de responsabilidad social, dedican un apartado a esta cuestión. Una infracción destinada a sancionar la falta de veracidad de estos informes o «publicidad» medioambiental no sólo serviría para tutelar un interés que es totalmente merecedor de protección penal, como es la transparencia social, sino que además situaría de nuevo el proceso penal en el país del cual procede la empresa matriz. Esta estrategia se ha puesto ya en marcha en algunos estados, como Francia, que obligan a publicar informes de responsabilidad social

(69) Cfr. Darnaculleta i Gardella, M., «Autorregulación, sanciones administrativas y sanciones disciplinarias», en Arroyo Jiménez, L. A. y Nieto Martín, A. (coords.), Autorregulación y sanciones, Lex Nova, Valladolid, 2008, pp. 120 y ss. 
corporativa, sancionando penalmente su inveracidad (70). En Estados Unidos, con una lógica similar, la empresa Nike fue acusada de publicidad engañosa, tras comprobarse que su actividad en países terceros imponía condiciones laborales muy distintas a las que aseguraba respetar en la información que ofrecía a los mercados acerca de su grado de compliance (71). Esta estrategia basada en la transparencia como forma de control social, es la adoptada por la Securities Law norteamericana(72) y que desde allí se ha extendió a casi todos los ordenamientos. Si bien, al día de hoy esta transparencia se refiere fundamentalmente a la transparencia financiera, nada impide su extensión a otros sectores de la actividad de la empresa como la transparencia medioambiental o social(73).

\section{BIBLIOGRAFÍA}

Abadie P., «A New Story of David and Goliath: The Alien Tort Claims Act Gives Victims of Environmental Injustice in the Developing World a Viable Claim Against Multinational Corporations», Golden Gate State University Law Review, Vol. 34, 2004.

Atapattu, S., «The Right to a Healthy Life or the Right to Die Polluted?: The Emergence of a Human Right under International Law», Tulane Environmental Law Journal, Vol. $16,2002-2003$.

BAIGÚN, D., «El Estatuto de Roma y la responsabilidad penal de las personas jurídicas», en Libro Homenaje al Prof. Marino Barbero Santos, Vol. I, Ed. de la Universidad de Castilla la Mancha, Cuenca, 2001.

Berat, L., «Defending the Right to a Healthy Environtment: Toward a Crime of Geocide in International Law», Boston University International Law Journal, Vol. 11, 1993.

Cabana, F., Responsabilidad penal del dirigente en estructuras jerárquicas, Tirant lo Blanch, 2003.

Calvo, L., Derecho internacional del medio ambiente, Atelier, Barcelona, 2005.

CAO, L., «The Transnational and Subnational in Global Crimes», Berkely J. Int. L., 2004.

Cassel, J., Enforcing Environmental Human Rights: Slected Strategies for US NGOs, Northwestern Journal of International Human Rights, Vol. 6, 2007.

Cassels, D., «Corporate Aiding and Abetting of Human Rights Violations: Confusion in the Courts», Journal of International Human Rights, Vol 6, Issue. 2, 2008.

Cassels, J., «Outlaws: Multinational Corporations and Catastrophic Law», Cumb. L. Rev., Vol. 31, 2000-2001.

Crusto, M., «Green Business: Should We Revoke Corporate Charters for Environmental Violations?», Louisiana Law Review, Vol. 63, 2002-2003.

(70) Artículo 148-2 del Código de Comercio, Decreto número 2002-221 de 20 de febrero de 2002 .

(71) Vid. JosePH, S., op. cit., pp. 101 y ss.

(72) Incluso en la SEC puede hablarse ya de una green disclousure, vid. Zondorak, V., op. cit., pp. 466 y ss.

(73) Vid. Crusto, M., «Green Business: Should We Revoke Corporate Charters for Environmental Violations?», Louisiana Law Review, Vol. 63, 2002-2003, p. 175; Williams, C., «The Securities Exchange Comission and Corporate Social Transparency», Harvard Law Review, Vol. 112, 1999, pp. 112 y ss. 
Darnaculleta i Gardella, M., «Autorregulación, sanciones administrativas y sanciones disciplinarias», en Arroyo Jiménez, L. A. y Nieto Martín, A. (coords.), Autorregulación y sanciones, Lex Nova, Valladolid, 2008.

DAvis, J., «Justice Without Borders: Human Rights Cases in U. S. Courts», Law \& Policy, Vol. 28, núm. 1, 2006.

Delage, G., «Le Droit pénal de l'environment, en Giudicelli Dellage (sous la direction)», Droit pénal des affaires en Europe, PUF, 2006.

Drumbl, M., «Waging War Against the World: The Need to Move from War Crimes to Environmental Crimes», Fordham Int'l L. J., Vol. 22, 1998-1999.

Eutenier, G., «Towards a Corporate Law of Nations, Multinational Enterprises' Contribution to Customary International Law», Tulane Law Review, vol. 82, 2007-2008.

FABIÁn CAPARRós, E., La corrupción de agente público extranjero e internacional, Tirant lo Blanch, 2003.

Fuchs, D., Business Power in Global Governance, Lynne Riener Publishers, 2007.

Gibbs, C.; Gore, M.; McGarrell, E., y Rivers, L., «Introducing Conservation Criminlogy», Brit. J. Criminol., Vol. 50, 2010.

Gray, M., «The International Crime of Ecocide», California Western International Law Journal, Vol. 26, 1995-1996.

Halsey, M., «Against "green” criminology», Brit. J. Criminol., Vol. 44, 2004.

Jescheck, H., Tratado de Derecho penal, Vol. 1 (trad. Muñoz Conde/Mir Puig), Bosch, 1981.

Joseph, S., Corporations and Transnational Human Rights Litigation, Hart Publishing, Oxford, 2004.

Kalas, P., «International Environmental Dispute Resolution and the Need for Access by Non Sate Entities», Colo. J. Int.'l Envtl. L. \& Pol, Vol. 21, 2001.

Kofele-Kale, N., The International Law of Responsibility for Economic Crimes, 2. ${ }^{a}$ ed., Ashgate, 2006.

Llados, B., Nuevas perspectivas de la política criminal europea en materia medioambiental, Atelier, 2008.

Martin, J., Strafbarkeit grenzüberschreitender Unweltbeeinträchtigungen, Freiburg, 1989.

Matas, D., La protección del medio ambiente en el Derecho Internacional Humanitario, Tirant lo Blanch, Valencia, 2005.

McCallion, K., y Sharma, R., «Environmental Justice without Borders: The Need for an International Court of the Environment to Protect Fundamental Environmental Rights», Geo. Wash. J. Int'1 L. \& Econ, Vol. 32, 1999-2000.

Ministry of Justice, The Bribery Act 2010: Guidance about procedures which relevant comercial organisations can put into place to prevent persons associated with them from bribing (section 9 of the Bribery Act 2010), 2011.

Moosmayer, K., Compliance: Praxisleitfaden für Unternhemen, Beck, München, 2010.

Morimoto, T., Growing industrialization and our damaged planet. The extraterritorial application of developed countries environmental law to transnational corporations abroad, Utrecht Law Rev., Vol. I, Issue 2, 2005.

Nieto Martín, A., Fraudes Comunitarios: Derecho penal económico europeo, Praxis, Barcelona, 1996.

— «Autorregulación, compliance y Justicia restaurativa», en Arroyo Jiménez, L. A. y Nieto Martín, A. (coords.), Autorregulación y sanciones, Lex Nova, Valladolid, 2008.

- La responsabilidad penal de las personas jurídicas: un modelo legislativo, Iustel, 2009. 
NowaK, M., Y Kosma, J. «A World Court of Human Rights», Swiss Initiative to Commemorate the 60th Anniversary of The UDHR: Protecting Dignity: An Agenda for Human Rights.

OrTs, E., «Reflexive Environmental Law», Northwestern University Law Journal, Vol. 89, 1994-1995.

OsoFsKy, H., «Learning from Environmental Justice: A Nex Model for International Environmental Rights», Standford Environmental Law Journal, Vol. 24, 2005.

Perce, F., y Tombs, S. «Bohpal: Union Carbide and the Hubris of the Capitalist Technocracy», Social Justice, Vol. 16, núm. 2, 1989.

RATNER, S., «Corporations and Human Rights: A Theory of Legal Responsibility», The Yale Law Journal, Vol. 111, 2001.

- Remarks by the President to the Nation on the BP Oil Spill, 15-10-2010, The White House, Office of the Press Secretary.

- Report of the International Commission of Jurist Experts Legal Panel on Corporate Complicity in International Crime, Ginebra, 2008.

Roв, W., «Environmental crime in global context», Current Issues Crim. Just., 16, 2004-2005.

SATZGER, H., Internationales und Europäisches Strafrecht, Nomos, 2010.

Schwabach, A., «Ecocide and Geocide in Iraq», Colo. J. Int'l Envt. L. \& Pol., Vol. 15, 2004.

Shanghnessy, «The United Nations Global Compact and then Continuing Debate about the Effectiviness of Corporate Voluntary codes of Conduct», Colo. J. Int'l Envtl. L. \& Pol., Vol. 12, 2001.

SHARP, P., «Prospects for Environmental Liability in the International Criminal Court», Virginia Environmental Law Journal, Vol. 18, 1999.

Sornarajah, M., «Transnational Crimes: The Third Limb of The Criminal Law», Singapore Journal of Legal Studies, 2004.

Stephens, B., «The Amorality of Profit: Transnational Corporations and Human Rights», Berkeley J. Int'l L., Vol. 20, 2002.

WANG, S., «New Developments of Environmental Policy and Environmental Criminal Law in the People's Republic of China», ZIS, 2010.

Williams, C., «The Securities Exchange Comission and Corporate Social Transparency», Harvard Law Review, Vol. 112, 1999.

ZondoRAK, V., «A new face in corporate environmental responsibility: The Valdez Principles», Environmental Affairs, Vol. 18, 1991.

ZubizARRETA, J., Las empresas transnacionales frente a los derechos humanos: la historia de una asimetría normativa, Hegoa, Bilbao, 2009. 